\title{
Micromole per Liter per Minute
}

National Cancer Institute

\section{Source}

National Cancer Institute. Micromole per Liter per Minute. NCI Thesaurus. Code C120852.

A concentration unit equal to one micromole of solute in one liter of solution per unit of time equal to one minute. 